\title{
Simulation in bronchoscopy training: are we there yet?
}

\author{
Henri G. Colt
}

Published online: 13 December 2012

(C) Springer Science+Business Media New York 2012

\begin{abstract}
The time has come for bronchoscopists around the world to recognize that simulation is the best alternative to learning on patients. Only in this way will patients no longer suffer the burden of procedure-related learning. Technical skills can be acquired, practiced, and improved by use of inanimate models and combinations of low and high-fidelity simulation, including increasingly portable computer-based trainers. Validated assessment tools and checklists can be used to measure a learner's progress towards competence, complementing assessments during direct observation and real patient experience. Simulation scenarios should include more than technical skill exercises, to encompass the full range of procedural practice. As simulation is increasingly incorporated into training programs, there is a need to use business ethics to enhance innovation and democratize new technology. Simulation in bronchoscopy training: we are not there yet, but we are certainly moving in the right direction.
\end{abstract}

Keywords Bronchoscopy $\cdot$ Education $\cdot$ Simulation · Checklists · Competency

\section{Introduction}

In 2007 Davoudi and Colt reviewed 10 papers published since 2001 pertaining to the use of simulation for bronchoscopy education [1]. This review described how simulation helps learners improve procedural efficiency and economy of movement, thoroughness, and accuracy of airway examination, reduces airway wall trauma, and enhances learner satisfaction

H. G. Colt $(\bowtie)$

University of California, Irvine,

Laguna Beach, CA 92651, USA

e-mail: Henricolt@gmail.com and interest [2-4]. By using simulation, bronchoscopists can repeatedly practice tasks under supervision or independently, eliminating risks to patients, and ensuring that patients no longer suffer the burden of procedure-related learning. Simulation scenarios and technical skill exercises can be adapted to an individual's specific needs consistent with a learner-centric approach to medical education. Objective assessments built into computer-based simulation or used by observer-trainers help identify errors and provide constructive feedback outside the patient setting.

High-fidelity simulation techniques incorporate threedimensional virtual anatomy and force feedback technology so learners can practice technical skills by use of a proxy bronchoscope (Fig. 1). Low-fidelity simulation techniques use inanimate models (or discarded animal parts) and real bronchoscopes for the same purpose (Fig. 2). The low-high fidelity nomenclature is probably misleading: inanimate models may actually simulate with greater reality the tactile feel of bronchoscopic inspection or needle insertion. In one study, an inexpensive low-fidelity airway model was shown to be superior to costly high-fidelity computer simulation for learning three different conventional transbronchial needle aspiration techniques $[5,6]$.

There are obvious advantages and disadvantages of both high and low-fidelity simulation. Historically, bronchoscopists have been introduced to a variety of procedural techniques by use of pig, sheep, dog, and human cadavers. Inanimate airway models obviate the need for animal or discarded animal parts, reduce training-related costs, and enable the use of training materials in hotel conference centers and non-hospital facilities. Inanimate models can be used to teach virtually all aspects of diagnostic and therapeutic bronchoscopy (Fig. 3).

Computer-based high-fidelity simulation is fashionable and expensive, but can be extremely beneficial. Ideally, case scenarios and assessment tools are built into the virtual model. A variety of tools are used to provide instantaneous 


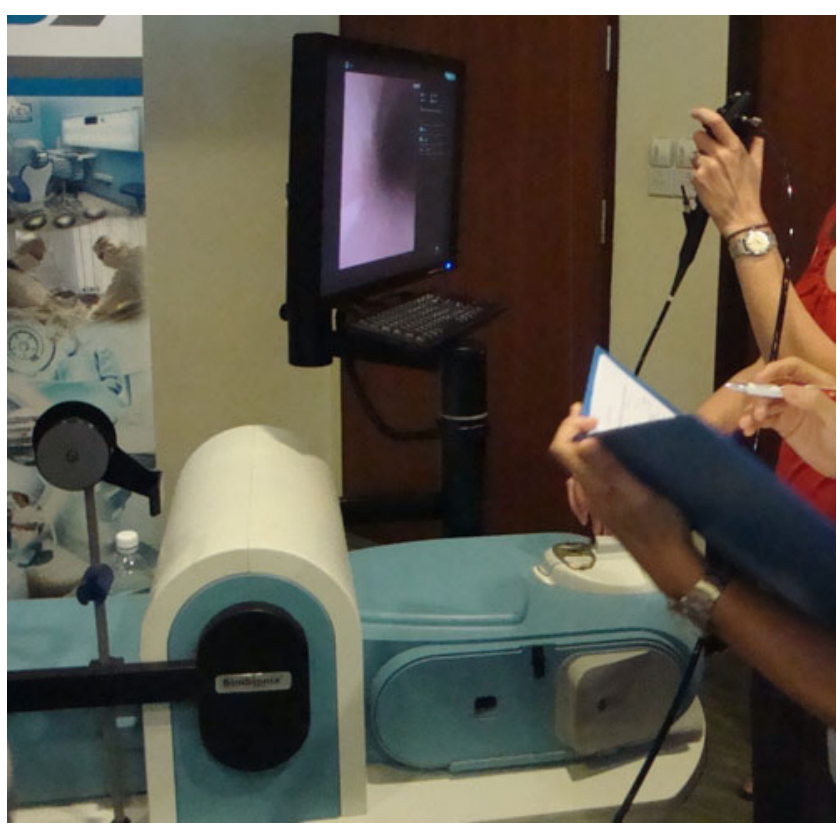

Fig. 1 Example of a high-fidelity computer-based simulator for endobronchial ultrasound

feedback without the need for a human instructor's presence. Pictorial realism and technical challenges inserted into these scenarios capture user interest. Scenarios are selected so learners can practice in settings that warrant different levels of skill and knowledge.

There are major obstacles to the implementation of simulation for bronchoscopy training: cost, product development with parallel distribution, and resistance to change. Affecting these obstacles is the paucity of knowledge regarding how simulation can be satisfactorily incorporated into learning programs. The purpose here is to review how obstacles can be overcome, while raising awareness of some

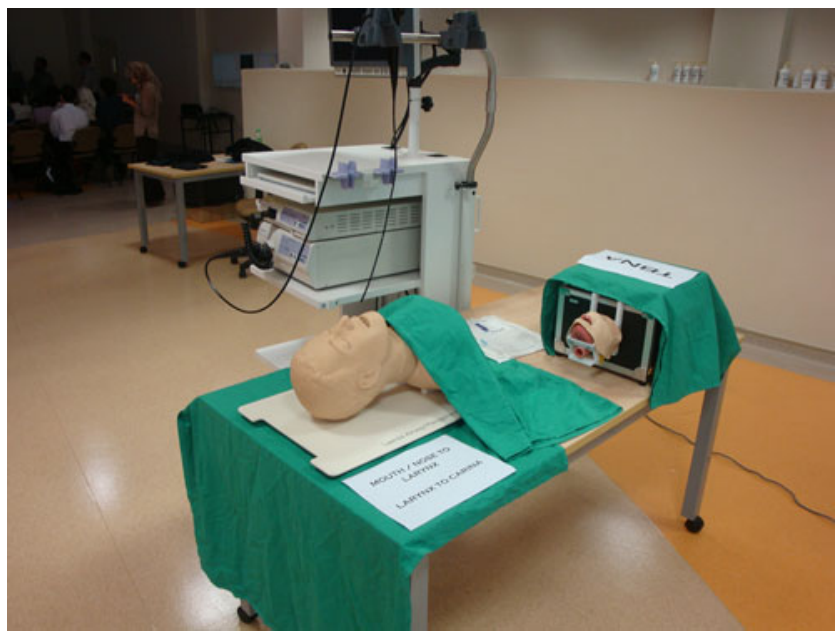

Fig. 2 Examples of low-fidelity models for teaching bronchoscopic inspection, conventional transbronchial needle aspiration, and endobronchial ultrasound

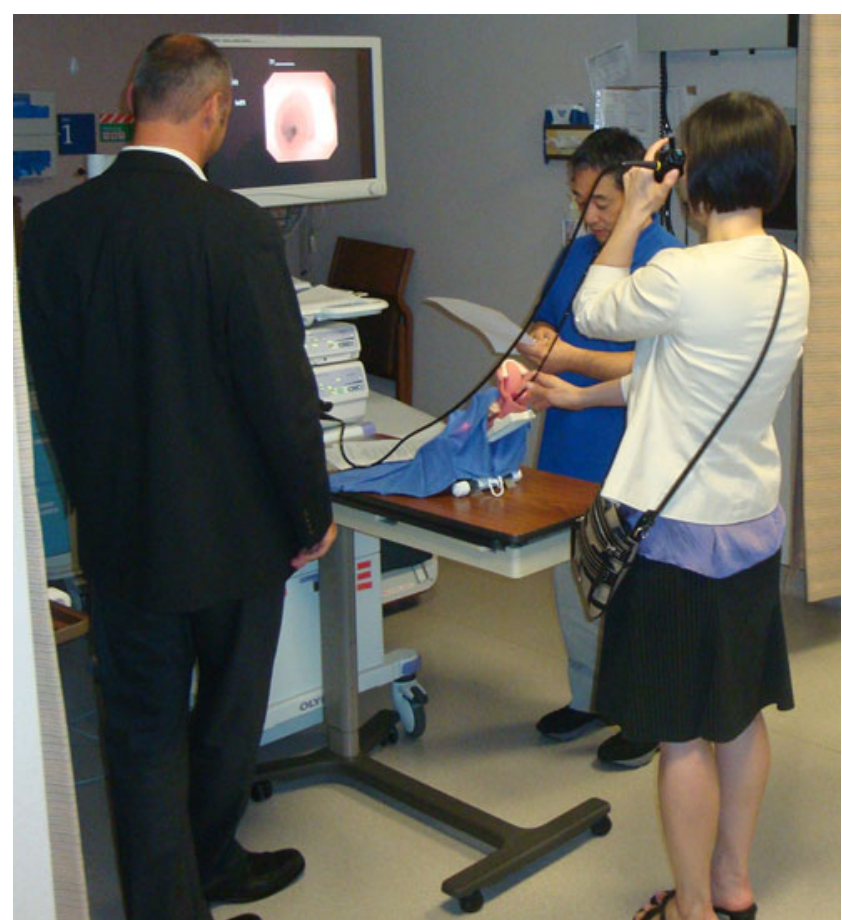

Fig. 3 Example of hands-on practice using an inanimate airway model during a faculty development program. Dr Hideo Saka (seen in photograph, with permission) is practicing using a validated bronchoscopy skills and tasks assessment tool checklist (BSTAT) [7] to assess a roleplaying faculty member's technical skill during inspection bronchoscopy

interesting new developments in the computer-based bronchoscopy simulation learning environment.

\section{Costs, product development, and parallel distribution}

The diversity of the bronchoscopy-related educational process arises from lack of uniform requirements, paucity of structured curricula, absence of validated measures of competence and proficiency, unequal access to learning materials, variability of patient-based learning experiences, and different skill, interest, and teaching ability of medical practitioners designated to be bronchoscopy instructors. To help remedy these deficiencies, training manuals, assessment tools, and checklists are proposed for use in training programs and postgraduate courses $[7,8 \bullet \bullet$. Investigators are studying the effects of their use on bronchoscopy knowledge and skill acquisition [9, 10]. A multifaceted program, for example the Bronchoscopy Education Project ${ }^{1}$ (World Association for Bronchology and Interventional Pulmonology) uses a combination of standardized didactic lectures modified on the basis of regional needs, web-based training videos, ${ }^{2}$ assessment tools, checklists, recommended reading

\footnotetext{
${ }^{1}$ WABIP at wabip.com

${ }^{2}$ YouTube BronchOrg video channel
} 
assignments, simulation scenarios, step-by-step technical skill exercises, ${ }^{3}$ and patient-centered practical approach exercises to enhance bronchoscopy-related knowledge.

High-fidelity simulators are very expensive. They are probably not cost-effective unless incorporated into a multidisciplinary simulation center program in which thoracic surgeons, anesthesiologists, and pulmonary-critical care bronchoscopists share the device. Cost-effectiveness is enhanced when simulators include software used by other specialists, for example gastroenterologists and urologists. This strategy works well when institutions have ample funds for a dedicated simulation center. Curricular design specialists are consulted to design, develop and implement such multidisciplinary programs.

Inanimate models have the advantage of being far less costly, easily transportable, and available for daily use within a single specialty. They are also applicable to a multidisciplinary simulation center's programs. Pulmonary departments that purchase these models provide their trainees with opportunities for guided and independent practice. Although no single model is perfect for every form of instruction, a combination of models is used to teach different aspects of different bronchoscopic procedures. This warrants a thoughtful approach to the training process in which techniques are deconstructed into component parts (a form of laddered learning). For wider use of inanimate models on a global scale, affordable products must be marketed to individual training institutions able to purchase them. Although some inanimate models of different construction and cost are available, a more consolidated strategic approach to expanding global services by manufacturers and professional respiratory societies is still lacking. As one expert has astutely noted, ${ }^{4}$ the inherently bioethical underpinning of the simulation dialog is:

1. preventing the waste of lives (human and animal);

2. reducing cost burden; and

3. wider potential expansion/democratization of knowledge.

\section{Overcoming resistance to change}

Human beings have a natural tendency to resist change. This seems to be particularly prevalent in the medical community.

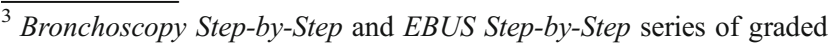
exercises help learners acquire the technical skills necessary for bronchoscopic inspection and endobronchial ultrasound-guided transbronchial needle aspiration. Instructional videos are viewable on desktop computers hand-held devices, iPads, or cell phones. Specific training maneuvers help the learner practice incrementally difficult steps of bronchoscopy and EBUS-TBNA. These are designed to enhance muscle memory by breaking down complex moves into constituent elements practiced repeatedly before being combined in more complex maneuvers.

${ }^{4}$ September Williams MD, personal communication
}

The history of medicine is full of examples of medical establishments resisting scientific progress running counter to convention wisdom. Traditionally conservative and cautious by nature, many physicians are reluctant to adopt new practices and ideas. They prefer to wait for sustainable and frequently reproducible research results before changing practices.

A common critique has been that simulation-enhanced knowledge and skill acquisition is not necessarily transferable to the bedside or real patients. Considering that the advantages of simulation-based training are well accepted in the military, the aviation industry, nuclear power plants, and in business and engineering, this argument carries little weight. Similar to what has occurred in these industries, checklists and assessment tools should probably be incorporated into the training setting to further strengthen simulation-based educational programs [11••, 12••]. Also, it is likely that business ethics need to be more broadly applied to expand innovation and democratize the technology before simulation becomes standard of practice for bronchoscopy education.

In The Tipping Point, Malcolm Gladwell writes that ideas, products, messages, and behavior spread like viruses in an epidemic. He describes the use of mavens (accumulators of knowledge), connectors (disseminators of knowledge), and salesmen (persuaders) to help make an idea stick. He suggests that although, intuitively, we might believe that change of any kind occurs gradually, in reality there should be “ ... no expectation about proportionality. We need to prepare ourselves for the possibility that sometimes big changes follow from small events, and that sometimes these changes can happen very quickly" [13]. He defines the Tipping Point as a moment of great sensitivity when any change can have enormous consequences. It is "the moment of critical mass, the threshold, the boiling point." [14]. After more than a decade of steady progression toward simulation training, I suggest we are nearing such a tipping point in our educational programs. To cite a phrase from Star Trek made famous in popular culture "resistance is futile" [15].

\section{Incorporating simulation into training programs}

The American philosopher John Dewey (1859-1952), wrote "the belief that all genuine education comes about through experience does not mean that all experiences are genuinely or equally educative" [16]. This is particularly true for experiences in simulated environments. One overhears instructors or course organizers mention their students are going to "play" at a technical skill station: until recently, few training programs or educational courses emphasized

\footnotetext{
${ }^{5}$ The Borg: phrase used to convey the inevitability of assimilation (Star Trek The next generation 1987-1994).
} 
specific learning objective technical skill stations or objectively measured whether knowledge and skill were acquired. By posting specific learning objectives, and making sure that learners have ample time to familiarize themselves with requested tasks, simulation-related learning experiences are incredibly enriching, beneficial, and fun.

One example of an effective curriculum might include scenarios that enable intentional repetition and reinforcement of specific skill sets. Checklists (Fig. 4) are used to ensure each step of a particular procedure is mastered before moving on to the subsequent step (another form of laddered learning). Assessment tools ${ }^{6}$ are used to monitor progress in learning, identify areas warranting remedial training, and provide opportunities for positive feedback and reinforcement (Fig. 5). Each learner's active engagement time, defined as the amount of time actually spent learning by the learner, is optimized by rewarding precourse preparation and focusing onsite learning on specific technical skill tasks that must be mastered. ${ }^{7}$

Instructors using such a multifaceted approach encourage learners to adopt simulation in a wide variety of settings, and not only for specific bronchoscopy-related technical skill acquisition. Problem-solving, informed consent, time out, moderate sedation, fluoroscopy, patient and familyencompassing decision making, communication skills, delivering bad news, conflict resolution (ethics), team-building skills, and systems-based practice can be addressed in a simulation environment incorporating individual and teambased exercises. Below is one example of a team-based simulation scenario pertaining to informed consent for endobronchial ultrasound bronchoscopy-guided transbronchial needle aspiration (EBUS-TBNA) (Fig. 6) [17].

\section{New developments in education, simulation, and computer gaming}

The experiential learning necessary to become a competent bronchoscopist includes passive experience (something that happens to or is delivered to the learner) and interactive processes (something in which the learner is actively engaged mentally and/or physically). Curriculum designers integrate

\footnotetext{
${ }^{6}$ A series of Bronchoscopy Assessment Tools provide objective measures with demonstrated validity and interobserver reliability. Fixed numeric and grade scores can be attributed to the learner on the basis of technical skills that include dexterity, accuracy, anatomic recognition and navigation, posture and position, economy of movement, and atraumatic instrument manipulation, pattern recognition, and image analysis.

${ }^{7}$ Tinsley and Lebak describe a zone of reflective capacity in which adults increase their ability for critical reflection using feedback, analyses, and evaluation of one another's work in a collaborative working environment (Lebak, K. \& Tinsley, R. Can inquiry and reflection be contagious? Science teachers, students, and action research. Journal of Science Teacher Education;2010:21;953-970).
}

simulation-based exercises into training programs to complement onsite learning based on a traditional apprenticeship model. Lessons learned through simulation are a helpful addition to a learner's cognitive, affective, experiential, and technical skill knowledge base.

By implementing simulation-based educational products, instructors gain experience with educational methodology and philosophy. The challenges facing academic faculty and course instructors make this difficult in today's busy practice environment; reduced dedicated opportunities for teaching, need for more efficient patient turn-around times, reduced patient lengths of stay, frequently uncertain rewards and incentives for teaching faculty, to name but a few. Well designed faculty development programs [18], also called "train-the-trainer" programs, that enable instructors to practice their teaching skills and share their experiences with colleagues are a welcome educational opportunity that ultimately benefits learners and patients.

For example, several teaching techniques described in general education can be used in medical procedure-based education [19]. Instructors might adopt a facilitator approach whereby learners first acquire knowledge by viewing video tapes or finishing reading assignments. This is followed by instructor-guided laddered learning assignments or technical skill tasks in which knowledge increases stepby-step. By use of a liberationist approach, on the other hand, instructors might challenge learners to discover a problem's solutions on their own. This problem-based learning technique prompts creativity and self-discovery. Rather than learn from instructor-led demonstrations or didactic intervention, learners are asked to teach themselves by use of a variety of different educational resources available via social media, published literature, and group interactions.

Several new developments suggest that bronchoscopy simulation's future is promising. Behance's real time fiberoptic bronchoscopy simulator game [20] uses 3D anatomical graphics and animation and runs on Microsoft's XBOX XNA. Objectives include navigating the airway with minimum discomfort and injury to the patient and accurate identification of anatomy within the throat, upper airway, and bronchi [21]. At Thoracic-anesthesia.com, a computerbased simulator was developed using real time video to help teach and review bronchoscopic anatomy. Anesthesiologists can thus improve their lung isolation management skills, leading to improved efficiency and patient safety. Navigation arrows embedded in Adobe Flash video enable operators to navigate through the airway [22]. Even a single simulated bronchoscopy was shown to heighten learner confidence when performing real-life procedures, and in one study $80 \%$ of respondents said they were "more confident" in their ability to achieve lung isolation after performing the simulation [23]. The highly portable Orsim bronchoscopy simulator runs on a laptop, yet offers complete virtual airway anatomy with high- 
Fig. 4 Example of the Informed Consent 10 point checklist used as part of The Bronchoscopy Education Project [17]

\section{INFORMED CONSENT 10-Point CHECKLIST*}

Learner Training Year

Faculty Date

Simulation Bronchoscopy Workshop $\square$ Patient-based Bronchoscopy Scenario

\begin{tabular}{|c|c|}
\hline $\begin{array}{c}\text { Educational Item* } \\
\text { Items } 1-10 \text { scored } 10 \text { points each (Partial points are possible) }\end{array}$ & $\begin{array}{l}\text { Satisfactory } \\
\text { Yes/No }\end{array}$ \\
\hline $\begin{array}{l}\text { 1. Able to define "Informed Consent": } \\
\square \text { Informed decision-making regarding indications and expected } \\
\text { outcomes, } \square \text { Conflict of interest } \square \text { Protection from liability } \\
\square \text { Provides opportunity to assess management strategies } \\
\square \text { Provides opportunity to discuss risks, benefits, and alternatives }\end{array}$ & Yes / No \\
\hline 2. Able to discuss diagnosis and pertinent clinical issues & Yes / No \\
\hline 3. Able to describe the purpose of the procedure & Yes / No \\
\hline 4. Able to describe the nature of the procedure & Yes / No \\
\hline 5. Able to describe procedure-related risks & Yes / No \\
\hline 6. Able to describe procedure-related benefits & Yes / No \\
\hline $\begin{array}{l}\text { 7. Able to describe alternative procedures regardless of cost } \\
\text { or health care coverage }\end{array}$ & Yes/No \\
\hline $\begin{array}{l}\text { 8. Able to describe potential risks and benefits from } \\
\text { choosing the alternatives }\end{array}$ & Yes / No \\
\hline $\begin{array}{l}\text { 9. Able to describe the risks and benefits of not performing } \\
\text { the procedure or not choosing any of the alternatives }\end{array}$ & Yes/No \\
\hline $\begin{array}{l}\text { 10. Able to demonstrate "effectiveness" of the informed } \\
\text { consent process by asking the patient to explain in his or her } \\
\text { own words, their understanding of the procedure }\end{array}$ & Yes / No \\
\hline
\end{tabular}

* Contains elements required by ACGME (patient care, medical knowledge, practice-based learning and improvement, interpersonal communication skills, professionalism, and systems-based practice).

FINAL GRADE PASS FAIL SCORE $/ 100$

quality 3D graphics, a replica bronchoscope, and the ability to score performance [24].

The WABIP Bronchoscopy Education Project [25] implemented in 2010 has successfully expanded a multidimensional educational program that includes assessment tools, training videos, a BronchAtlas video series, a collection of Fundamentals of Bronchoscopy PowerPoint lectures, patient-centered practical approach exercises, and The Essential Bronchoscopist series of books and training manuals ${ }^{8}$ developed by Bronchoscopy International. Courses and faculty development programs have been held all over the world with the assistance of certified

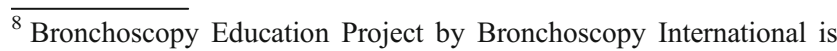
licensed under a Creative Commons Attribution-NoncommercialShare Alike 3.0 United States License.
} 
Fig. 5 Example of the EBUSSTAT (EBUS skills and tasks assessment tool) checklist used as part of the Bronchoscopy Education Project [17]
EBUS-STAT 10 Point Assessment Tool

Learner:

Year of Training

Faculty

Date

\begin{tabular}{|c|c|}
\hline $\begin{array}{l}\text { Educational Item* } \\
\text { Items } 1-10 \text { each scored separately }\end{array}$ & $\begin{array}{l}\text { Satisfactory } \\
\text { Yes/No }\end{array}$ \\
\hline $\begin{array}{l}\text { 1. Able to maneuver the scope through upper airway into trachea, without } \\
\text { trauma or difficulty (5 points for single item tested) } \\
\square \text { Mouth and Vocal cords } \quad \square \text { ET Tube } \square \text { Laryngeal mask airway }\end{array}$ & $\begin{array}{l}\text { Yes / No } \\
\text { Score } \quad / 5\end{array}$ \\
\hline $\begin{array}{l}\text { 2. Able to maneuver scope using white light bronchoscopy within } \\
\text { tracheobronchial tree without trauma ( } 4 \text { points, no partial points) } \\
\square \text { Scope centered in airway lumen avoiding airway wall trauma }\end{array}$ & $\begin{array}{l}\text { Yes / No } \\
\text { Score } \quad / 4\end{array}$ \\
\hline $\begin{array}{l}\text { 3. Ultrasound image obtained without artifacts ( } 5 \text { points, no partial points) } \\
\square \text { Absence of artifacts on image, any target }\end{array}$ & $\begin{array}{l}\text { Yes / No } \\
\text { Score } \quad / 5\end{array}$ \\
\hline $\begin{array}{l}\text { 4. Identify major mediastinal vascular structures (4 points per item) } \\
\square \text { Aorta } \square \text { Pulmonary artery } \square \text { Superior vena cava } \square \text { Azygos vein } \square \text { Left atrium }\end{array}$ & $\begin{array}{l}\text { Yes } / \text { No } \\
\text { Score } \quad / 20\end{array}$ \\
\hline $\begin{array}{l}\text { 5. Identify lymph node station (Select } 3 \text { targets, } 5 \text { points each) } \\
\begin{array}{ll}\square \mathrm{R} \quad \square 2 \mathrm{~L} \quad \square 4 \mathrm{R} \quad \square 10 \mathrm{R} \quad \square 7 \quad \square 4 \mathrm{~L} \quad \square 10 \mathrm{~L} \quad \square 11 \mathrm{~L} \quad \square 11 \mathrm{Rs} \quad \square 11 \mathrm{Ri}\end{array}\end{array}$ & \begin{tabular}{|l|l} 
Yes $/$ No \\
Score $\quad / 15$
\end{tabular} \\
\hline $\begin{array}{l}\text { 6. Able to operate EBUS processor (2 points each item) } \\
\square \text { Gain } \quad \square \text { Depth } \quad \square \text { Doppler }\end{array}$ & $\begin{array}{l}\text { Yes / No } \\
\text { Score } \quad / 6\end{array}$ \\
\hline $\begin{array}{l}\text { 7. Performance of EBUS-TBNA (1 point each, target } 15 \text { points) } \\
\square \text { Advance needle through working channel (neutral position) } \square \text { Secure needle } \\
\text { housing by sliding the flange } \square \text { Release sheath screw } \square \text { Advance and lock sheath } \\
\text { when it touches wall } \square \text { Release needle screw } \square \text { Advance needle using jab } \\
\text { technique } \square \text { Visualize needle entering target node } \square \text { Move stylet in and out a few } \\
\text { times } \square \text { Remove stylet } \square \text { Attach syringe } \square \text { Apply suction } \square \text { Pass needle in and } \\
\text { out of node 10-15 times } \square \text { Release suction } \square \text { Retract needle into sheath } \square \\
\text { Unlock and remove needle and sheath }\end{array}$ & $\begin{array}{l}\text { Yes / No } \\
\text { Score } \quad / 15\end{array}$ \\
\hline $\begin{array}{l}\text { 8. Image analysis: CT scans (1 point each, target } 10 \text { points) } \\
\square \text { Image } 1 \square \text { Image } 2 \quad \square \text { Image } 3 \square \text { Image } 4 \square \text { Image } 5 \square \text { Image } 6 \square \text { Image } 7 \\
\square \text { Image } 8 \square \text { Image } 9 \square \text { Image } 10\end{array}$ & $\begin{array}{l}\text { Yes / No } \\
\text { Score } \quad / 10 \\
\end{array}$ \\
\hline $\begin{array}{l}\text { 9. Image analysis: EBUS views (1 point each, target } 10 \text { points) } \\
\square \text { Image } 1 \square \text { Image } 2 \quad \square \text { Image } 3 \square \text { Image } 4 \square \text { Image } 5 \square \text { Image } 6 \square \text { Image } 7 \\
\square \text { Image } 8 \square \text { Image } 9 \square \text { Image } 10\end{array}$ & $\begin{array}{l}\text { Yes } / \text { No } \\
\text { Score } \quad / 10 \\
\end{array}$ \\
\hline 10. Decision-making tasks: ( 2 points each, target 10 points) & Yes / No \\
\hline$\square$ Image $1 \quad \square$ Image $2 \quad \square$ Image $3 \quad \square$ Image $4 \quad \square$ Image 5 & Score $\quad / 10$ \\
\hline
\end{tabular}

FINAL GRADE PASS FAIL SCORE $/ 100$

Copyright Bronchoscopy International

instructors and in collaboration with universities and regional or national bronchology and pulmonary societies.

As the medical education model shifts to one of demonstrable competency-based learning [26, 27], educators must adapt to a rapidly evolving information-technology and computer-simulation environment. Bronchoscopes and bronchoscopic procedures are changing as manufacturers move into GPS-like navigational devices, 3D stereoscopic instruments with enhanced optics, and multimodality devices that incorporate optical and acoustic and nano technology. Concurrently, educational opportunities are increasing because of new educational techniques, easily transportable and less expense computer-based simulators, and wider dissemination of affordable inanimate models [28, 29].

\section{Conclusion}

In this paper, reiteration of existing simulation-related literature retrievable by use of search engines and medical libraries has been avoided to focus instead on issues hindering global adoption of bronchoscopy simulation as the primary method of procedure-based education. Some of these issues are related to human factors; others are the result of realistic economic, 


\section{Team-based simulation scenario pertaining to informed consent for endobronchial ultrasound bronchoscopy-guided transbronchial needle aspiration}

\section{Case Title:}

Informed Consent in a patient with suspected bronchogenic carcinoma referred for EBUS-TBNA of mediastinal adenopathy

Applicable to the following learning groups:

Pulmonary and Thoracic Surgery specialists

\section{Educational Rationale:}

There has been little or no emphasis on methods for obtaining informed consent for interventional pulmonary procedures, including EBUS-TBNA. We believe that developing and applying guidelines for informed consent is necessary in view of the increasing number and complexity of interventional procedures to ensure that specific information about each procedure, as well as benefits, potential complications, and alternatives are shared with the patient. In addition, in an environment that respects cultural diversity, this information should be shared in respect with patient-defined goals, values and priorities, including participation of family members, when desired or warranted, in the information sharing and decision-making process.

\section{Learning Objectives:}

- The learner should be able to characterize the informed consent process according to accepted criteria

- The learner should be able to characterize the informed consent process in the setting of an emergency airway procedure where interaction is only possible with a family member.

Guided Study Questions:

- What are the key elements of informed consent?

- In respect for cultural diversity, what elements should be taken into consideration?

Learning materials to be reviewed prior to workshop participation

- Informed consent/research and procedures: read the essay from The Picture of Healtb: Medical ethics and the movies (Oxford University Press). View film clip from the film Extreme Measures.

- Braddock CH et al, How doctors and patients discuss routine clinical decisions. J. Gen Intern Med 1997;12:339-345

- Ness D. et al. Why does informed consent fail? J Am Acad Psychiatry Law 2009;37:349-362

Assessment Instruments used:

- Informed consent checklist (Figure 4)

Preparation and time of simulation (allow 30 minutes total):

\begin{tabular}{|l|l|}
\hline Set-up/instructions & 5 minutes \\
\hline Preparation & 2 minutes \\
\hline Simulation & 10 minutes \\
\hline Debrief & 10 minutes \\
\hline
\end{tabular}

\section{Specific instructions:}

The instructor will read the scenario to the team. A specially trained patient educator will be the subject of the simulation. A team member will be designated to lead the simulation, while other members of the team observe and use the informed consent ten point checklist to monitor performance

Simulation scenario:

A 74 year old male a history of weight loss has been diagnosed with a lung mass and mediastinal adenopathy on PET-CT. He is referred for EBUS-TBNA for diagnosis and possible staging. You must obtain informed consent from the patient for EBUS-TBNA in order to determine the cause of these radiographic findings.

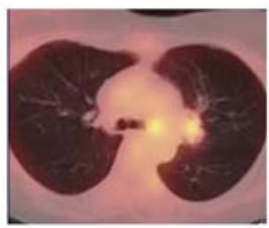

\section{Debriefing:}

Elements of informed decision making include: (1) discussion of the clinical issue; (2) description of the procedure; (3) discussion of the risks and potential benefits of the procedure; (4) discussion of therapeutic alternatives and potential consequences from choosing those alternatives; (5) discussion of the implications of declining treatment;(6) assessment of the patient's and/or family member's understanding, (7) discussion of the uncertainties associated with the decision; (8) asking the patient and family to express a preference.

\section{Copyright Bronchoscopy InternationalO}

Fig. 6 Example of informed consent simulation scenario used as part of the Bronchoscopy Education Project [17] 
logistic, and organizational obstacles. Either way, these issues are responsible for a resounding "NO" in answer to the question simulation in bronchoscopy training: are we there yet?

But, we are on the right track. Opinion leaders have begun advocating simulation in pulmonary and critical care training programs, in part inspired by results from a few bronchoscopy simulation-related publications, advances in simulation technology, and successful applications of simulation in surgery and anesthesia. Assessment tools and checklists are increasingly valued; enthusiasm aroused in part by their well publicized and documented effectiveness in several training programs, operating theaters, and airplane cockpits. A renewed focus on professionalism and competency-based training raises justifiable ethical concerns about the learning by doing model obliging patients to suffer the burden of procedure-related practice. National and international societies have recognized that simulation attracts members to organized instructional activity, generates revenue, and helps these societies achieve their educational objectives. Such organizations as the World Association for Bronchology and Interventional Pulmonology are enhancing bronchoscopy-related services and accelerating the speed with which new technology is brought to the bedside by offering resources, training, and faculty development programs free or at very low cost to health-care providers, irrespective of location or type of practice. Finally, as individuals growing up with an experiential knowledge of video games and extraordinarily innovative methods of animation, simulation, and nonmedical technical skill acquisition enter the bronchoscopy workforce, any previously guarded adherence to more traditional teaching methods used in medical education will prove to be naturally ephemeral.

Disclosure Dr. Colt is chairman of the World Association for Bronchology and Interventional Pulmonology. He is also the founder of Bronchoscopy International, a transnational nonprofit organization.

\section{References}

Papers of particular interest, published recently, have been highlighted as:

•- Of major importance

1. Davoudi M, Colt HG. Bronchoscopy simulation: a brief review. Adv Health Sci Educ. 2009;14:287-96.

2. Ost D, DeRosiers A, Britt EJ, et al. Assessment of a bronchoscopy simulator. Am J Respir Crit Care Med. 2001;164(12):2248-55.

3. Crawford SW, Colt HG. Virtual reality and written assessments are of potential value to determine knowledge and skill in flexible bronchoscopy. Respiration. 2004;71:269-75.

4. Colt HG, Crawford SW, Galbraith O. Virtual reality bronchoscopy simulation: a revolution in procedural training. Chest. 2001;120(4):1333-9.

5. Goldberg R, Colt HG, Davoudi M, Cherisson L. Realistic and affordable lo-fidelity model for learning transbronchial needle aspiration. Surg Endosc. 2009;23(9):2047-52.
6. Davoudi M, Wahidi MM, Rohani NZ, Colt HG. Comparative effectiveness of low and high-fidelity bronchoscopy simulation for training in conventional transbronchial needle aspiration and user preferences. Respiration. 2010;80:327-34.

7. Davoudi M, Osann K, Colt HG. Validation of two instruments to assess technical bronchoscopy skill using virtual reality simulation. Respiration. 2008;76:92-101.

8. •• Konge L, Larsen KR, Clementsen P, et al. Reliable and valid assessment of clinical bronchoscopy performance. Respiration. 2012;83(1):53-60. Study confirming the potential role of assessment instruments in bronchoscopy education.

9. Colt HG, Davoudi M, Murgu S, Rohani NZ. Measuring learning gain during a one-day introductory bronchoscopy course. Surg Endosc. 2010;25:207-16.

10. Konge L, Clementsen P, Richter Larsen K, et al. Establishing pass/fail criteria for bronchoscopy performance. Respiration. 2012;83:140-6.

11. •• Davoudi M, Colt HG, Osann KE, et al. Endobronchial ultrasound skills and tasks assessment tool. Am J Respir Crit Care Med. 2012;186(8):773-9. Validation study of an assessment tool to objectively measure skill levels in EBUS and EBUS-TBNA. Assessment instruments can be used to plot progress during learning and identify areas requiring further instruction.

12. • Haynes AB, Weiser TG, Berry WR, et al. Changes in safety attitude and relationship to decreased postoperative morbidity and mortality following implementation of a checklist-based surgical safety intervention. BMJ Qual Saf. 2011;20:102e107. This article describes the importance if using checklists to enhance patient safety.

13. Gladwell M. The tipping point. New York: Little, Brown and Company; 2000. p. 11.

14. Gladwell M. The tipping point. New York: Little, Brown and Company; 2000. p. 12.

15. http://en.wikipedia.org/wiki/Borg_(Star_Trek) Accessed November 13, 2012.

16. Dewey J. Experience and education. The Kappa Delta Pi Lecture Series. New York: Touchstone Books; 1997. p. 25.

17. Colt HG. Endobronchial Ultrasound Training Manual. Bronchoscopy International, pg. Laguna Beach; 2012. p. 75-78.

18. Colt HG. Faculty Development Training Manual eBook. Bronchoscopy International, pg. Laguna Beach; 2012. p. 93.

19. Fenstermacher GD, Soltis JF. Approaches to teaching. 5th ed. New York: Teachers College Press; 2009. p. 31.

20. http://www.behance.net/gallery/Real-Time-Fiber-Optic-BronchoscopySimulator/3285796.

21. http://snehapai.com/74739/662184/all/bronchoscopy-simulator Downloaded November 13,2012.

22. http://www.thoracic-anesthesia.com/?page_id=2. Downloaded November 13, 2012.

23. http://www.anesthesiologynews.com/View Article.aspx? $\mathrm{d}=$ Technology\&d_id=8\&i=November $+2011 \& \mathrm{i}$ id $=785 \& \mathrm{a}$ id=19656 Accessed November 13, 2012.

24. http://www.orsim.co.nz/ Accessed November 13, 2012.

25. http://www.bronchoscopy.org Accessed November 13, 2012.

26. Carraccio C, Wolfsthal SD, Englander R, et al. Shifting paradigms: from flexner to competencies. Acad Med. 2002;77(5):361-7.

27. Wahidi MM, Silvestri GA, Coakley RD, et al. A prospective multicenter study of competency metrics and educational interventions in the learning of bronchoscopy among starting pulmonary fellows. Chest. 2010;137(5):1040-9.

28. Colt HG, Quadrelli S. Democratization of medical knowledge and technology: brief commentary on implications for medical education. Simul Healthc. 2006;1:238-9.

29. Krogh CL, Konge $L$ et al. Training on a new, portable, simple simulator transfers to performance of complex bronchoscopy procedures. Published online August 20, 2012, doi: 10.1111/j.1752699X.2012.00311.x. 